\title{
Anaplastic oligoastrocytoma
}

INSERM

\section{Source}

INSERM. (1999). Orphanet: an online rare disease and orphan drug data base. Anaplastic oligoastrocytoma. ORPHA:251663

Anaplastic olig oastrocytoma is a rare and aggressive glial tumor of the central nervous system, that usually presents in adults with seizures, is most often located in the cerebral hemispheres and that is associated with a very poor prognosis. 